Article

\title{
Spectrophotometric Study of Bridging $N$-Donor Ligand-Induced Supramolecular Assembly of Conjugated Zn-Trisporphyrin with a Triphenylamine Core
}

\author{
Nirmal K. Shee, Ju-Won Seo and Hee-Joon Kim *D
}

check for updates

Citation: Shee, N.K.; Seo, J.-W.; Kim, H.-J. Spectrophotometric Study of Bridging N-Donor Ligand-Induced Supramolecular Assembly of Conjugated Zn-Trisporphyrin with a Triphenylamine Core. Molecules 2021, 26, 4771. https://doi.org/10.3390/ molecules26164771

\section{Academic Editors: João Paulo}

C. Tomé, Augusto C. Tomé and Elena Cariati

Received: 29 June 2021

Accepted: 4 August 2021

Published: 6 August 2021

Publisher's Note: MDPI stays neutral with regard to jurisdictional claims in published maps and institutional affiliations.

Copyright: (c) 2021 by the authors. Licensee MDPI, Basel, Switzerland. This article is an open access article distributed under the terms and conditions of the Creative Commons Attribution (CC BY) license (https:// creativecommons.org/licenses/by/ $4.0 /)$.
Department of Applied Chemistry, Kumoh National Institute of Technology, Gumi 39177, Korea; nirmalshee@gmail.com (N.K.S.); juwon1105@gmail.com (J.-W.S.)

* Correspondence: hjk@kumoh.ac.kr; Tel.: +82-54-4787822

\begin{abstract}
This article studies the supramolecular assembly behavior of a Zn-trisporphyrin conjugate containing a triphenylamine core (1) with bridging $N$-donor ligands using the UV-vis spectrophotometric titration method at micromolar concentrations. Our results show that pyridine, a non-bridging ligand, formed a 3:1 open complex with 1 . The corresponding binding constant was estimated to be $(2.7 \pm 0.15) \times 10^{14} \mathrm{M}^{-3}$. In contrast, bridging ligands, 4,4-bipyridine (BIPY) and 1,3-di(4pyridyl)propane (DPYP), formed stable 3:2 double-decker complexes with 1 in solution, which collapsed to yield a 3:1 open complex when excess BIPY or DPYP was added. The binding constants for forming BIPY and DPYP double-decker complexes were estimated to be $(9.26 \pm 0.07) \times 10^{27} \mathrm{M}^{-4}$ and $(3.62 \pm 0.16) \times 10^{27} \mathrm{M}^{-4}$, respectively. The UV-vis titration profiles supported the conclusion that the degradation of the 3:2 double-decker 1.BIPY complex is less favorable compared to that of 1.DPYP. Consequently, the formation of the 3:1 1.DPYP open complex proceeded more readily than that of $1 \cdot B I P Y$.
\end{abstract}

Keywords: Zn-trisporphyrin conjugate; supramolecular assembly; bridging $N$-donor ligand; doubledecker complexes

\section{Introduction}

The construction of well-defined nano- and microscopic architectures provides access to outstanding materials [1-3] for use in artificial electron transfer [4], photocatalysis [5], sensing [6], molecular recognition [7], and medicinal applications [8]. Porphyrin materials are attractive building blocks for forming self-assembled, highly ordered supramolecular structures [9-11]. Porphyrin compounds are important because of their symmetric aromatic structures and excellent electronic and photophysical properties, and are used for catalysis [12-14]. Porphyrin molecules self-assemble to form large-scale aggregates with welldefined nanostructures of definite sizes, shapes, and dimensions. Various intermolecular non-covalent forces or interactions, such as hydrogen bonding, hydrophobic or hydrophilic interactions, $\pi-\pi$ stacking, ligand coordination, electrostatic interactions, and van der Waals interactions, are responsible for porphyrin self-assembly [15-19]. Various strategies, such as ionic self-assembly [20], re-precipitation methods [21], ligand coordination [22], coordination polymerization [23], and surfactant assistance by either surfactants or amphipathic molecules [24], have been utilized to form porphyrin aggregates. However, covalent metalloporphyrins, such as dendrimers, double-stranded conjugated ladder porphyrins, porphyrin arrays, double-decker porphyrins, cyclic porphyrins, and tetra-porphyrins, readily self-assemble without any external stimuli and form a larger aggregation of porphyrin arrays in solution [25-30]. Among the various supramolecular architectures, trismetalloporphyrins assembled with $N$-donor ligands, such as 1,4-diazabicyclo[2.2.2] octane (DABCO), form sandwich-type coordination cages that are attractive for supramolecular catalysis applications and artificial molecular receptor synthesis [31-33]. 
We have previously reported the strong two-photon absorption of octupolar trisporphyrin conjugates containing a triphenylamine core (1) (Scheme 1) [34]. The optimized geometry obtained using semi-empirical AM1 calculations revealed that the trisporphyrin molecule adopts a propeller-shaped structure. Incorporating the unique $C_{3}$-symmetrical structure of conjugated porphyrins, we expected to construct an interesting architecture via supramolecular assembly within this system. In this report, we describe the spectrophotometric study of the supramolecular assembly of Zn-trisporphyrin induced by coordination with bridging $N$-donor ligands. We chose 4,4-bipyridine (BIPY, a rigid ligand) and 1,3-di(4pyridyl)propane (DPYP, a flexible ligand) as the bridging $N$-donor ligands for the present study.

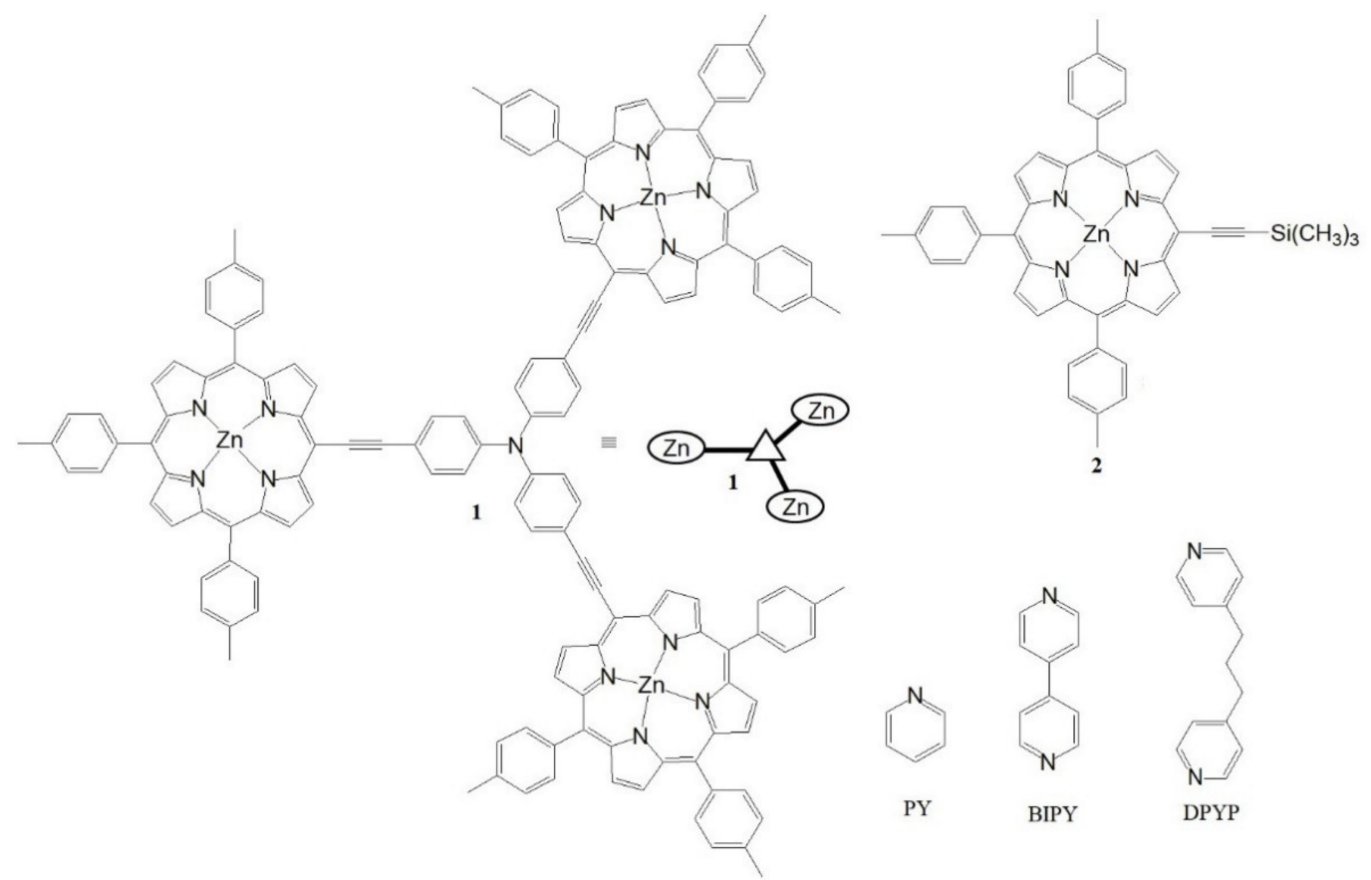

Scheme 1. Chemical structures of Zn-porphyrins and $N$-donor ligands used in this study.

\section{Results and Discussion}

UV-vis spectroscopy was applied to evaluate the binding properties of Zn-trisporphyrin 1 $\left(1 \times 10^{-6} \mathrm{M}\right)$ with bridging $N$-donor ligands in toluene at room temperature. For a comparative study, we used monomeric Zn-porphyrin 2 ([5,10,15-tri-( $p$-tolyl)-20-trimethylsilylethyny lporphyrinato]Zn(II), see Scheme 1) as a reference model and performed supramolecular assembly studies under similar conditions.

The stability constant and the related species resulting from the coordination of pyridine with $\mathbf{1}$ are shown in Scheme 2. The UV-vis spectrum of $\mathbf{1}$ in toluene contained an intense, broad Soret band (439 nm) and weak Q-bands (570 nm and $627 \mathrm{~nm}$ ) (Figure 1 and Supplementary Materials Figure S1) [34]. 


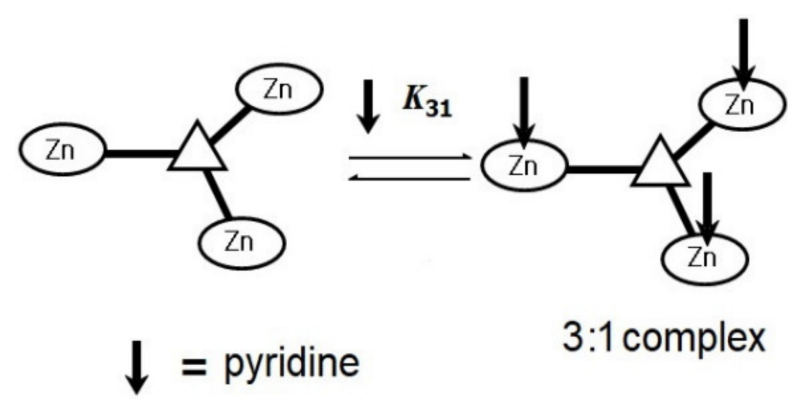

Scheme 2. Schematic representation of the species involved in the binding of Zn-trisporphyrin 1 with pyridine.
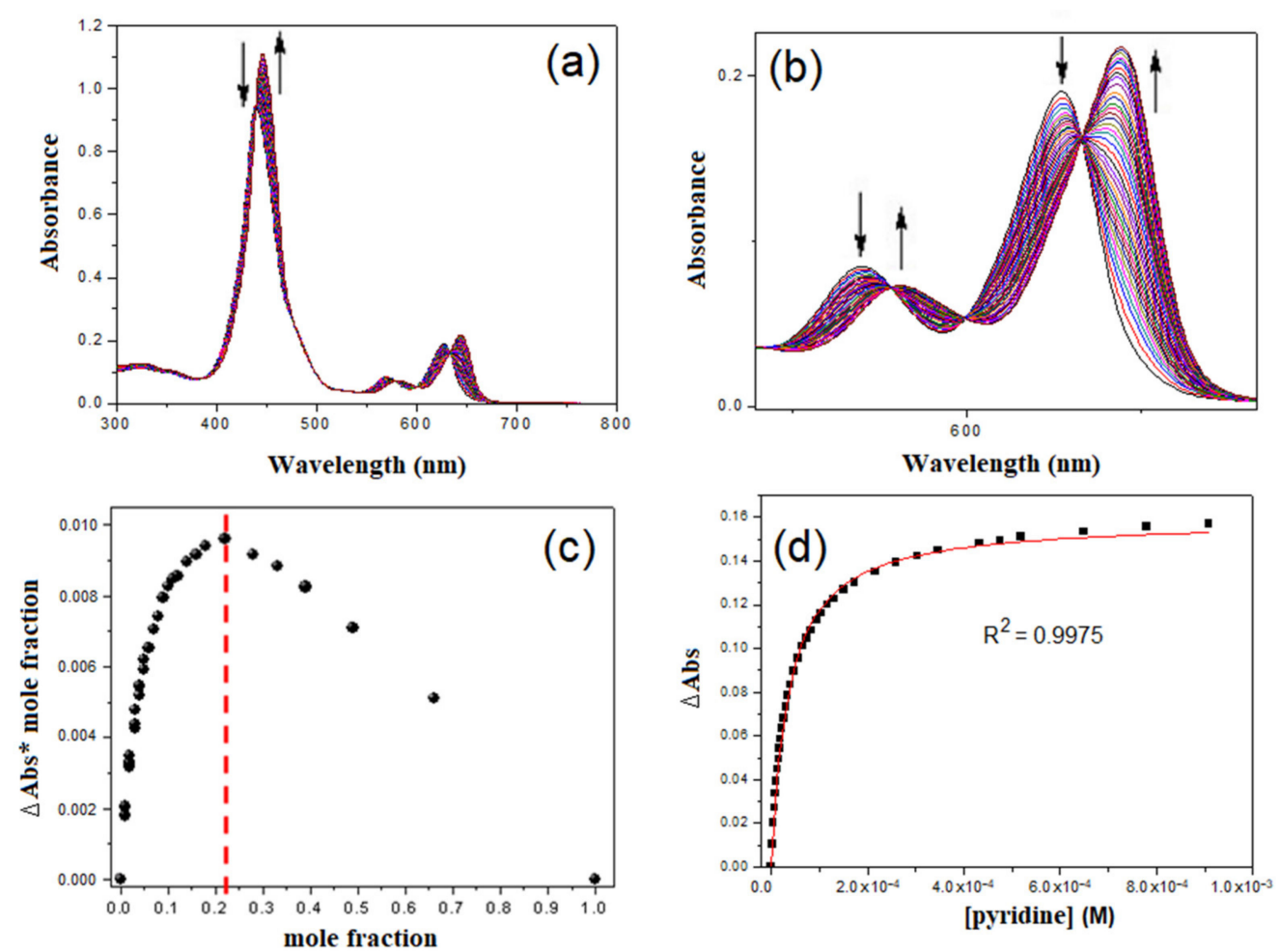

Figure 1. UV-vis titration spectra of Zn-trisporphyrin 1 complexation with pyridine in toluene ( $c=1 \mu \mathrm{M}$ ). (a) UV-visible region, (b) Q-band zone, (c) data curve for Job's plot at $446 \mathrm{~nm}$ (mole fraction of 1), (d) fitting curve for the determination of the binding constant $K_{31}$ at $446 \mathrm{~nm}$.

Titrimetric addition of pyridine to a toluene solution of $\mathbf{1}$ created a series of isosbestic points $(439,578,599$, and $632 \mathrm{~nm}$ ) along with a shift in the Soret band (439 to $446 \mathrm{~nm}$ ) and in the Q-bands ( 570 to $581 \mathrm{~nm}$ and 627 to $644 \mathrm{~nm}$ ). The associated $7 \mathrm{~nm}$ redshift in the Soret band indicated pyridine binding to 1 . No further changes in the absorbance were observed after the addition of 3 equiv. of pyridine. Job's plot for the titration data (Figure 1c) clearly supports forming a 3:1 complex, as shown in Scheme 2. Equilibrium constant $K_{31}$ for $\mathbf{1}$-pyridine was calculated as follows:

$$
K_{31}=\left[(\mathrm{PY})_{3} \cdot \mathbf{1}\right] /[\mathrm{PY}]^{3}[1]
$$

The binding constant, $\boldsymbol{K}_{31}$ for the $\mathbf{1} \cdot$ pyridine complex, was estimated to be $(2.7 \pm 0.15)$ $\times 10^{14} \mathrm{M}^{-3}$. On the other hand, monomeric Zn-porphyrin 2 exhibits typical electronic absorption features in toluene, including an intense Soret band at $434 \mathrm{~nm}$ and weak $\mathrm{Q}$ bands at $563 \mathrm{~nm}$ and $605 \mathrm{~nm}$ (Figure S2). The addition of pyridine to a toluene solution of monomeric 2 resulted in a series of isosbestic points $(436,570,592$, and $611 \mathrm{~nm})$ along with a shift in the Soret band ( 434 to $438 \mathrm{~nm}$ ) and in the Q-bands (563 to $575 \mathrm{~nm}$ and 605 to 
$622 \mathrm{~nm}$ ). The associated $4 \mathrm{~nm}$ redshift in the Soret band is characteristic of the formation of a 2.pyridine complex in a 1:1 ratio. The binding constant, $K_{11}(=[\mathrm{PY} \cdot 2] /[\mathrm{PY}][2])$ for the 2.pyridine complex, was calculated to be $(1.60 \pm 0.08) \times 10^{4} \mathrm{M}^{-1}$ (Figure S2).

The addition of 4,4-bipyridine (BIPY) to a toluene solution of conjugated Zn-trisporphyrin $\mathbf{1}$ led to forming a series of coordination complexes. The overall stability constants and associated species are depicted in Scheme 3. The general equilibrium constants, shown in Scheme 3, were determined as follows:

$$
\begin{gathered}
K_{31}=\left[\mathrm{L}_{3} \cdot \mathbf{1}\right] /[\mathrm{L}]^{3}[\mathbf{1}] \\
K_{32}=\left[\mathrm{L}_{3} \cdot \mathbf{1}_{2}\right] /[\mathrm{L}]^{3}[\mathbf{1}]^{2} \\
K_{32 \leftrightarrow 31}=\left(K_{31}\right)^{2} /\left(K_{32}\right)=\left[\mathrm{L}_{3} \cdot \mathbf{1}\right]^{2} /\left[\mathrm{L}_{3} \cdot \mathbf{1}_{2}\right][\mathrm{L}]^{3}
\end{gathered}
$$

where, L = BIPY or DPYP.

\section{3:2 double-decker complex}

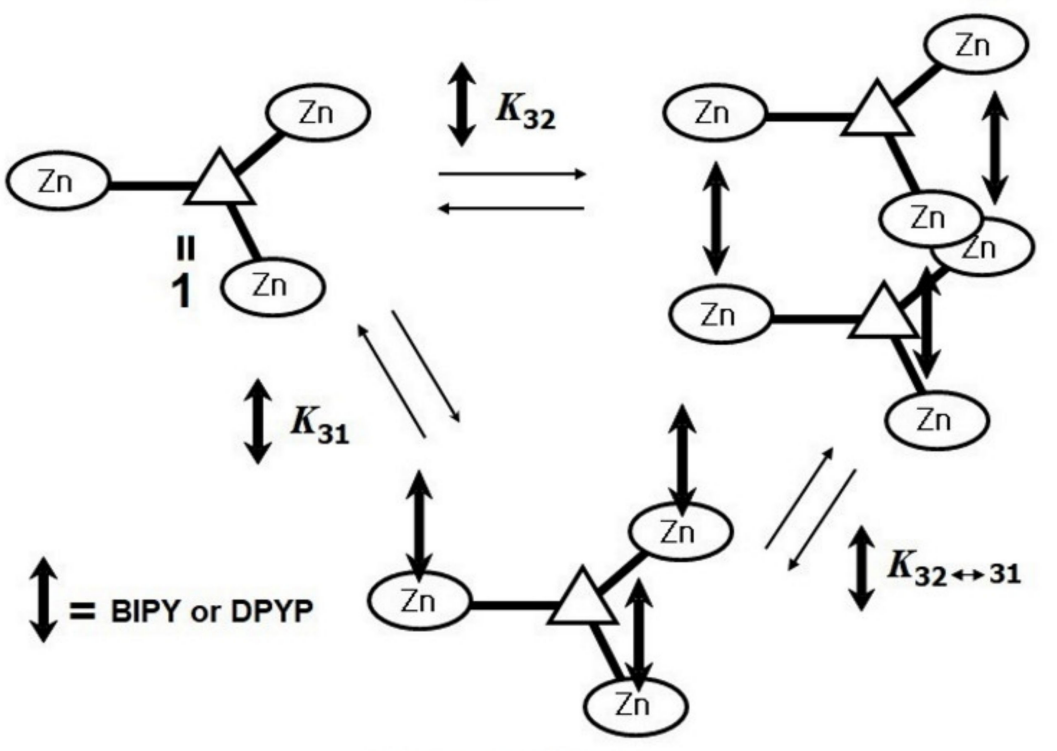

\section{3:1 open complex}

Scheme 3. Schematic representation of the species involved in the binding of Zn-trisporphyrin 1 with BIPY or DPYP.

Upon the addition of $0-3$ equiv. of BIPY into a toluene solution of 1 , the Soret band initially shifted from 439 to $443 \mathrm{~nm}$ (Figure 2 and Figure S3). Such a $4 \mathrm{~nm}$ redshift was characteristic of the formation of a 3:2 double-decker complex, as shown in Scheme 3. With the further addition of BIPY above 3 equiv. to the solution of 1, the band at $443 \mathrm{~nm}$ started to decrease in intensity, and a new band appeared at $446 \mathrm{~nm}$, suggesting the deconstruction of the 3:2 double-decker complex and the mono-coordination of $\mathbf{1}$ with BIPY to form a 3:1 open complex. In addition, a series of isosbestic points $(441,581,599$, and $634 \mathrm{~nm})$ along with a shift in the Q-bands (570 to $583 \mathrm{~nm}$ and 627 to $647 \mathrm{~nm}$ ) were also observed during the titration process. Based on the fitting of the titration data to the three species (1, 3:2 double-decker coordination complex, and 3:1 open complex) and the binding model described in Scheme 3, binding constants $K_{32}$ and $K_{31}$ were calculated to be $(9.26 \pm 0.07)$ $\times 10^{27} \mathrm{M}^{-4}$ and $(3.1 \pm 0.13) \times 10^{15} \mathrm{M}^{-3}$, respectively, using global multivariate factor analysis [31-33,35-37]. On the other hand, the BIPY titration of a toluene solution of monomeric 2 resulted in a two-phase absorbance change, which appeared stable even after the addition of more than 3 equiv. of BIPY. The titration results consisted of four concomitant isosbestic points $(436,570,592$, and $611 \mathrm{~nm})$ along with a shift in the Soret band (434 to $438 \mathrm{~nm}$ ) and in the Q-bands (563-575 $\mathrm{nm}$ and 605-622 nm). The associated 
$4 \mathrm{~nm}$ redshift in the Soret band evidently supports forming a 1:1 2.BIPY complex. From the titration data, it is clear that forming a 2:1 complex of Zn-monomeric 2 with BIPY was negligible under our experimental conditions. It is likely that 2:2 or 4:2 complexes were generated, which would affect the binding constant, as mentioned in the literature [32]. However, we did not consider these species owing to their negligible concentration under our experimental conditions (micromolar concentrations and room temperature). At micromolar concentrations, ladder-type 2:1 complexes are not likely to be formed during UV-visible titration [38]. The binding constant, $K_{11}(=[\mathrm{BIPY} \cdot 2] /[\mathrm{BIPY}][2])$ for $2 \cdot \mathrm{BIPY}$, was calculated to be $(2.02 \pm 0.03) \times 10^{4} \mathrm{M}^{-1}$ (Figure S4). The above observation confirmed that the synergistic effect of the three conjugated porphyrin moieties in $\mathbf{1}$ was operational during the titration process [26]. This cooperative effect facilitates constructing a 3:2 double-decker coordination complex at a certain concentration of BIPY in solution.
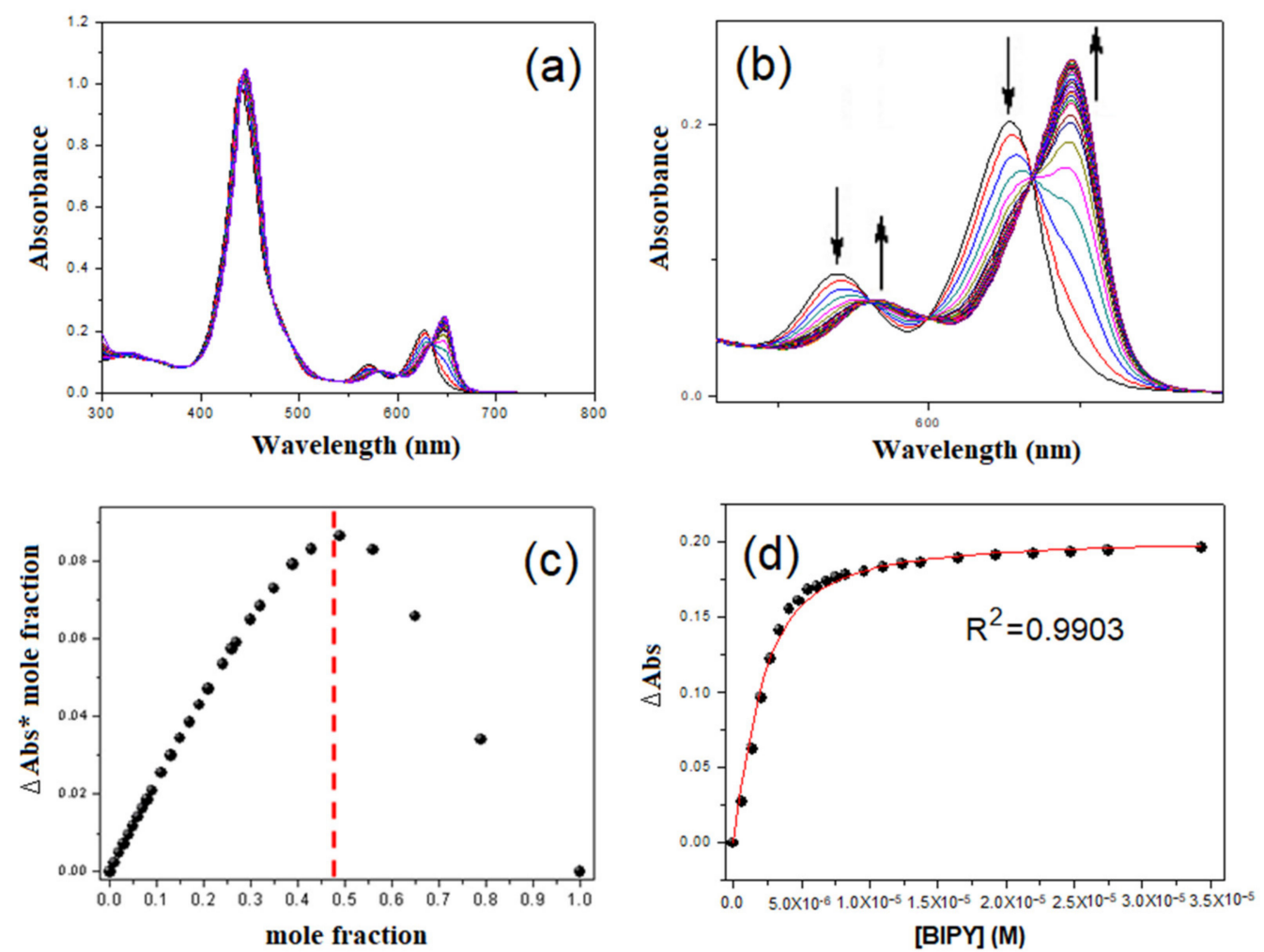

Figure 2. UV-vis titration spectra of Zn-trisporphyrin 1 with BIPY in toluene ( $c=1 \mu \mathrm{M})$. (a) UV-vis region, (b) Q-band zone, (c) data curve for Job's plot at $446 \mathrm{~nm}$ (mole fraction of $\mathbf{1}$ ), (d) fitting curve for the determination of the binding constant $K_{32}$ at $446 \mathrm{~nm}$.

The binding of the rigid ligand BIPY to 1 was then compared to the assembly behavior of 1 with flexible $\mathrm{N}$-donor ligand, 1,3-di(4-pyridyl)propane (DPYP) in toluene. Titrimetric addition of DPYP to a toluene solution of 1 gave rise to a series of isosbestic points $(439,579$, 599 , and $633 \mathrm{~nm}$ ) along with a shift in the Soret band ( 439 to $446 \mathrm{~nm}$ ) and in the Q-bands (570 to $582 \mathrm{~nm}$ and 627 to $645 \mathrm{~nm}$ ). The appearance of the titration profile was very similar to that of BIPY with 1 (Figures 3 and 4), although the fitted curve did not perfectly match with experimental data. This deviation may be due to side reactions that form unexpected complexes. 

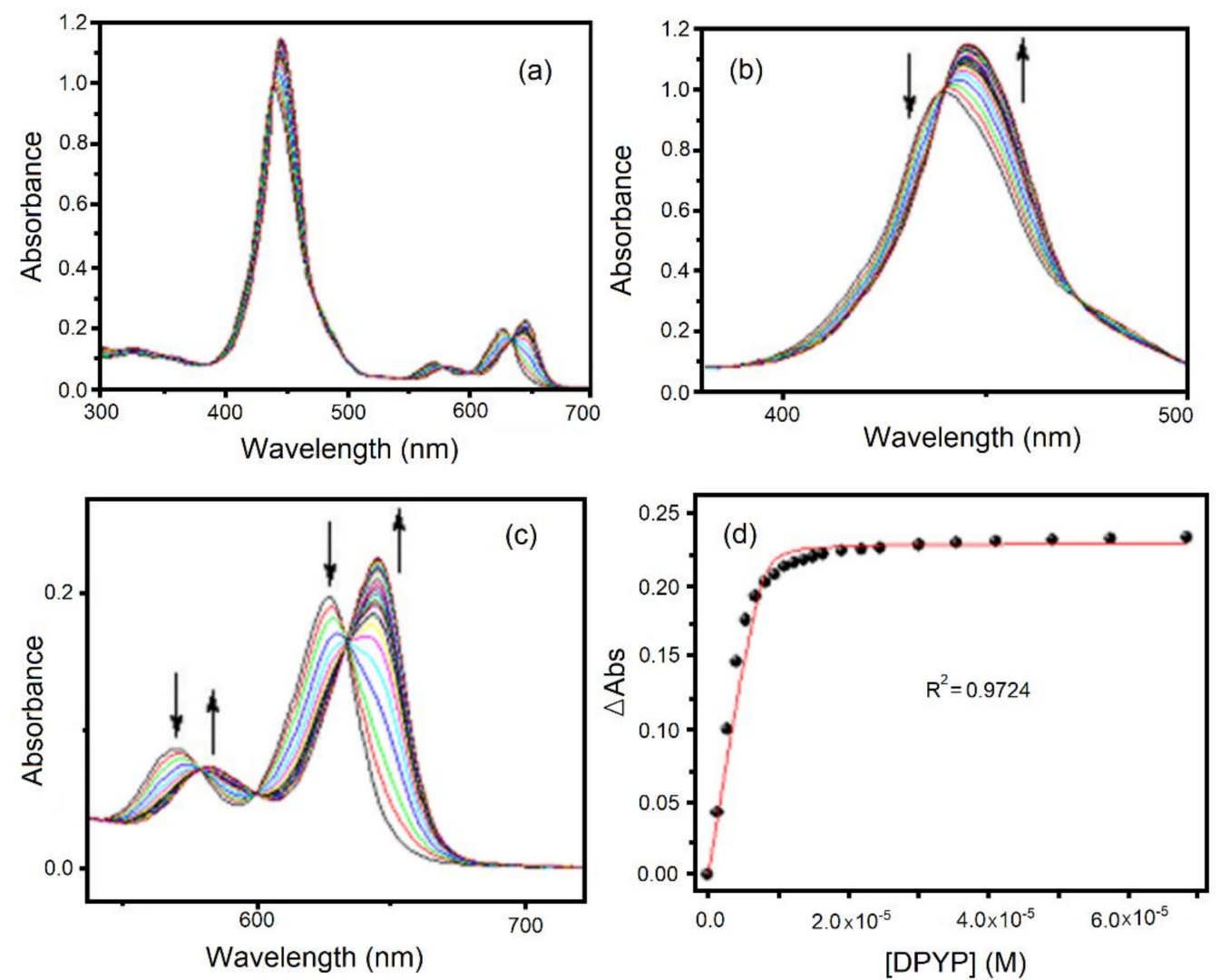

Figure 3. UV-vis titration spectra of Zn-trisporphyrin 1 with DPYP in toluene $(c=1 \mu \mathrm{M})$. (a) UVvisible region, (b) Soret-band zone, (c) Q-band zone, (d) fitting curve for the determination of the binding constant $K_{32}$ at $446 \mathrm{~nm}$.
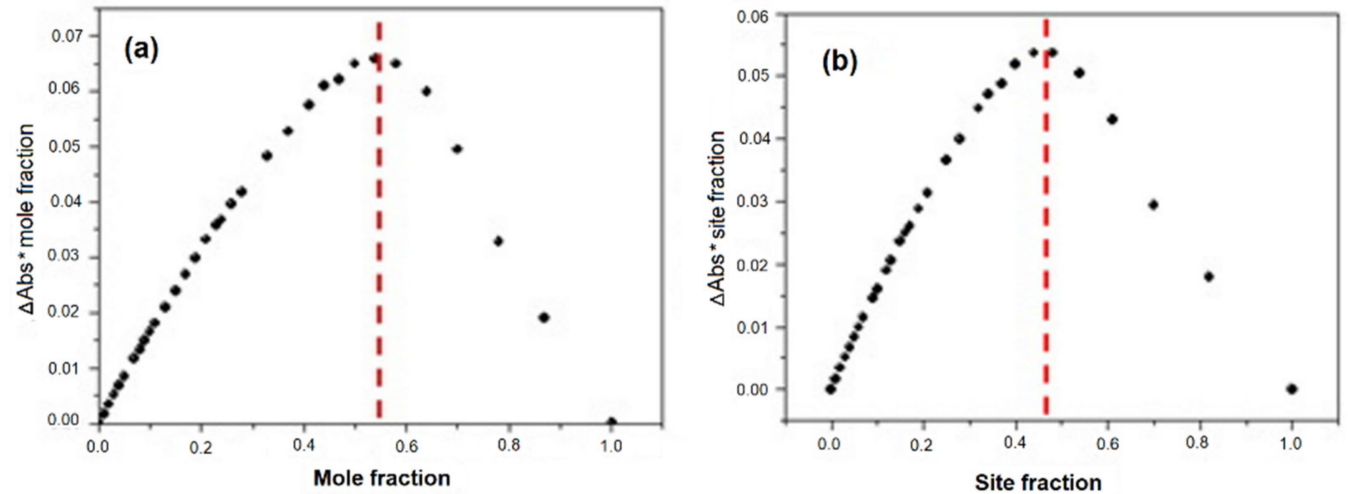

Figure 4. Job's plots for the UV-vis titration of Zn-trisporphyrin 1 with DPYP in toluene $(c=1 \mu \mathrm{M})$. (a) mole fraction, and (b) site fraction.

A notable difference is that the degradation of the sandwiched 3:2 complex and forming an open 3:1 complex proceeded more easily in the case of DPYP addition to the solution of 1 compared to that of BIPY titration. Binding constants $K_{32}$ and $K_{31}$ were calculated to be $(3.62 \pm 0.16) \times 10^{27} \mathrm{M}^{-4}$ and $(8.1 \pm 0.13) \times 10^{15} \mathrm{M}^{-3}$, respectively. Thus, the binding constant, $K_{32}$ of $\mathbf{1} \cdot \mathrm{BIPY}$, was approximately 2.5 times higher than that of 1.DPYP. This implies that rigid BIPY forms a more robust self-assembled double-decker complex than flexible DPYP. Using the above stability constants of 1.BIPY and 1.DPYP, and the SPECFIT program, we simulated the speciation profile considering only three species (1, 3:2 sandwiched complex, and 3:1 open structure) according to the reported methods [32,33], as shown in Figure 5. It should be mentioned that for simplicity, we neglected other species ( 2:2 or 4:2 model structures mentioned in [32]), due to their 
negligible content at micromolar concentration. We observed some notable features from these simulated speciation profiles along with the experimental spectra in Figures 2 and 3. Initially, the concentration of 1 is high $(100 \%)$, as indicated by the Soret band at $439 \mathrm{~nm}$. After the addition of ligands (BPY or DPYP), the Soret band is redshifted to $443 \mathrm{~nm}$, and the concentration of $\mathbf{1}$ is decreased. This is because, at a low concentration of ligand, both BIPY and DPYP formed 3:2 double-decker complexes with 1. The concentration of the 3:2 double-decker complex increased upon the addition of bidentate ligands up to 3 equivalents. The 3:2 double-decker complex seems to be stable up to a certain range of ligand concentrations. After that, these double-decker complexes gradually degrade to form 3:1 open complexes as the concentration of ligands highly increases further. The Soret band was further redshifted from $443 \mathrm{~nm}$ to $446 \mathrm{~nm}$ during this process.
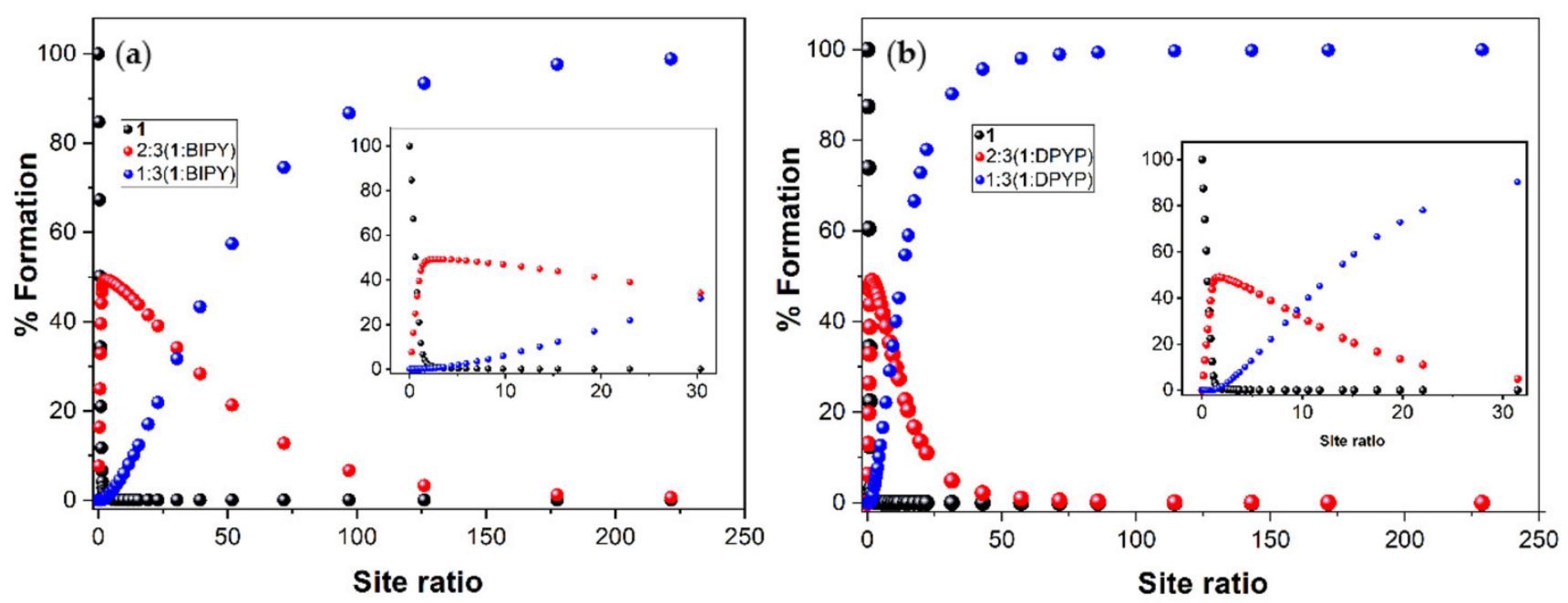

Figure 5. Simulated speciation profiles for titrations of $\mathbf{1}$ with (a) BIPY and (b) DPYP. Insets show enlargements of the lower-site-ratio region.

Several notable conclusions can be drawn from these UV-vis titration profiles. Degradation of the 3:2 double-decker 1-BIPY complex is less favorable compared to that of 1.DPYP. Consequently, forming the 3:1 open 1.DPYP complex proceeded more readily than that of 1.BIPY. It should be noted that DPYP is somewhat curved, whereas BIPY is a categorically linear ligand. Therefore, the possible geometry of the double-decker 3:2 1.BIPY complex would be a regular sandwich (eclipsed stacked structure). On the other hand, the double-decker 3:2 1.DPYP complex would exhibit offset sandwich geometry (displaced stacked structure).

To validate our results, we employed $\mathrm{DABCO}$, a common bridging ligand, previously used to construct double-decker complexes [31-33,36]. Titrimetric addition of DABCO to a toluene solution of 1 afforded a series of isosbestic points $(439,578,598$, and $632 \mathrm{~nm})$ along with a shift in the Soret band (439 to $446 \mathrm{~nm}$ ), as well as in the Q-bands (570 to $582 \mathrm{~nm}$ and 627 to $645 \mathrm{~nm}$ ). The appearance of the titration profile was comparable to that of BIPY titration of 1 (Figure S5). Binding constants $K_{32}$ and $K_{31}$ were calculated to be (1.47 \pm 0.09$)$ $\times 10^{27} \mathrm{M}^{-4}$ and $(1.7 \pm 0.21) \times 10^{15} \mathrm{M}^{-3}$, respectively. The binding constant, $K_{32}$ derived from 1.BIPY, was higher than that from 1.DABCO. Compared to DABCO, the longer arm of BIPY appears to avoid steric clashing with the aryl groups of $\mathbf{1}$ in forming double-decker complexes.

\section{Materials and Methods}

Zn-trisporphyrin conjugate $\mathbf{1}$ and monomeric Zn-porphyrin $\mathbf{2}$ were synthesized according to our previous report [34]. All other chemicals (pyridine, 4,4-bipyridine, and 1,3-di(4-pyridyl)propane) were purchased from Sigma-Aldrich and used without further purification. Steady-state UV-vis spectra were recorded on a Shimadzu UV-3600 spec- 
trophotometer. For UV-vis titrations, we prepared the host and guest solutions in toluene at room temperature. The porphyrin (host) concentration was fixed at $1 \mu \mathrm{M}$, and ligand (guest) concentration was varied from 0.001 to $0.1 \mathrm{M}$. UV-vis titration experiments were performed by recording a spectrum of the host (porphyrin) in toluene at $298 \mathrm{~K}$ and adding the guest (ligand) solution in increments. After each addition, a new UV-vis spectrum was obtained. The data obtained from the UV-vis spectrophotometric titrations were analyzed by fitting the entire spectral series at $1 \mathrm{~nm}$ intervals using the SPECFIT software [39], as mentioned in earlier reports [32,33]. To determine the binding constants, the titration results were fitted using the nonlinear regression method within the Origin 9 software and generated the following equation:

$$
\begin{gathered}
\mathrm{y}=\mathrm{A}\left((1+K \mathrm{x}+K \mathrm{P})-\left((1+K \mathrm{x}+K \mathrm{P})^{2}-4 K^{2 \mathrm{P}} \mathrm{x}\right)^{0.5} / 2 K \mathrm{P}\right. \\
\mathrm{x}=[\text { guest }] \times(\text { binding site }) \\
\mathrm{y}=\Delta \mathrm{A}=\mathrm{A}-\mathrm{A}_{0} \\
\mathrm{~A}=\Delta \mathrm{A} \text { at } 100 \% \text { complexation } \\
K=\text { Binding constant } \\
\mathrm{P}=[\text { host }]
\end{gathered}
$$

\section{Conclusions}

In summary, the supramolecular assembly of conjugated Zn-trisporphyrin $\mathbf{1}$ with different types of $\mathrm{N}$-donor ligands was investigated in solution at micromolar concentrations, employing UV-vis spectrophotometric titration. While pyridine, a non-bridging ligand, forms a 3:1 open complex with 1, bridging ligands, BIPY, and DPYP, form stable 3:2 double-decker complexes with 1 . These double-decker complexes collapse into simple open 3:1 complexes with the addition of excess BIPY or DPYP. For DPYP (flexible ligand) complexation with 1, the 3:2 double-decker complex equilibrated with the 3:1 open complex more readily than the 1.BIPY complex (rigid ligand). Additionally, forming a 3:2 doubledecker coordination complex was similarly observed when the DABCO complexed with 1. Our results provide valuable insights for constructing a variety of metalloporphyrin-based self-assembled structures, potentially applicable in constructing novel functional materials for chemical detection, supramolecular catalysis, and photoelectronics.

Supplementary Materials: The following are available online. Figure S1: UV-vis titration spectra of Zn-trisporphyrin 1 with pyridine in toluene; Figure S2: UV-vis titration spectra of Zn-monoporphyrin 2 with pyridine in toluene; Figure S3: UV-vis titration spectra of Zn-trisporphyrin 1 with 4,4bipyridine in toluene; Figure S4: UV-vis titration spectra of Zn-monoporphyrin 2 with 4,4-bipyridine in toluene, Figure S5: UV-vis titration spectra of Zn-trisporphyrin 1 with DABCO in toluene.

Author Contributions: Formal analysis, data curation, visualization, software, and writing, N.K.S.; Investigation, methodology, J.-W.S.; conceptualization, project administration, supervision, funding acquisition, resources, review, validation, and editing, H.-J.K. All authors have read and agreed to the published version of the manuscript.

Funding: This work was supported by the Kumoh National Institute of Technology (Grant No. 202001330001).

Data Availability Statement: Data are available in the article and Supplementary Materials.

Acknowledgments: We would like to thank S.Y. Jang for assistance with the titration experiments.

Conflicts of Interest: The authors declare no conflict of interest.

Sample Availability: Samples of the compounds are not available from the authors. 


\section{References}

1. Vantomme, G.; Meijer, E.W. The construction of supramolecular systems. Science 2019, 363, 1396-1397. [CrossRef] [PubMed]

2. Lehn, J.-M. Perspectives in Supramolecular Chemistry-From Molecular Recognition towards Molecular Information Processing and Self-Organization. Angew. Chem. Int. Ed. Engl. 1990, 29, 1304-1319. [CrossRef]

3. Wang, S.-P.; Lin, W.; Wang, X.; Cen, T.-Y.; Xie, H.; Huang, J.; Zhu, B.-Y.; Zhang, Z.; Song, A.; Hao, J.; et al. Controllable hierarchical self-assembly of porphyrin-derived supra-amphiphiles. Nat. Commun. 2019, 10, 1399-1411. [CrossRef] [PubMed]

4. Liu, Y.; Chen, Q.; Cullen, D.A.; Xie, Z.; Lian, T. Efficient Hot Electron Transfer from Small Au Nanoparticles. Nano Lett. 2020, 20, 4322-4329. [CrossRef]

5. Li, C.; Park, K.-M.; Kim, H.-J. Ionic assembled hybrid nanoparticle consisting of tin(IV) porphyrin cations and polyoxomolybdate anions, and photocatalytic hydrogen production by its visible light sensitization. Inorg. Chem. Commun. 2015, 60, 8-11. [CrossRef]

6. Qi, Z.-L.; Cheng, Y.-H.; Xu, Z.; Chen, M.-L. Recent advances in porphyrin-based materials for metal ions detection. Int. J. Mol. Sci. 2020, 21, 5839. [CrossRef] [PubMed]

7. Sun, H.; Ren, J.; Qu, X. Carbon Nanomaterials and DNA: From Molecular Recognition to Applications. Acc. Chem. Res. 2016, 49, 461-470. [CrossRef]

8. Montaseri, H.; Kruger, C.A.; Abrahamse, H. Recent advances in porphyrin-based inorganic nanoparticles for cancer treatment. Int. J. Mol. Sci. 2020, 21, 3358. [CrossRef] [PubMed]

9. Drain, C.M.; Varotto, A.; Radivojevic, I. Self-organized porphyrinic materials. Chem. Rev. 2009, 109, 1630-1658. [CrossRef]

10. Beletskaya, I.; Tyurin, V.S.; Tsivadze, A.Y.; Guilard, R.; Stern, C. Supramolecular chemistry of metalloporphyrins. Chem. Rev. 2009, 109, 1659-1713. [CrossRef]

11. Sun, Y.; Chen, C.; Liu, J.; Liu, L.; Tuo, W.; Zhu, H.; Lu, S.; Li, X.; Stang, P.J. Self-Assembly of Porphyrin-Based Metallacages into Octahedra. J. Am. Chem. Soc. 2020, 142, 17903-17907. [CrossRef]

12. Kim, M.K.; Shee, N.K.; Lee, J.; Yoon, M.; Kim, H.-J. Photoinduced electron transfer upon supramolecular complexation of (porphyrinato)Sn-viologen with cucurbit[7]uril. Photochem. Photobiol. Sci. 2019, 18, 1996-2002. [CrossRef]

13. Shee, N.K.; Kim, M.K.; Kim, H.-J. Fluorescent chemosensing for aromatic compounds by a supramolecular complex composed of tin(iv) porphyrin, viologen, and cucurbit[8]uril. Chem. Commun. 2019, 55, 10575-10578. [CrossRef]

14. Shee, N.K.; Kim, H.-J. Self-Assembled Nanomaterials Based on Complementary Sn(IV) and Zn(II)-Porphyrins, and Their Photocatalytic Degradation for Rhodamine B Dye. Molecules 2021, 26, 3598. [CrossRef]

15. Kim, H.-J.; Jo, H.J.; Kim, J.; Kim, S.-Y.; Kim, D.; Kim, K. Supramlecular self-assembly of tin(IV)porphyrin channels stabilizing single-file chains of water molecules. CrystEngComm 2005, 7, 417-420. [CrossRef]

16. Lee, S.J.; Malliakas, C.D.; Kanatzidis, M.G.; Hupp, J.T.; Nguyen, S.T. Amphiphilic porphyrin nanocrystals: Morphology tuning and hierarchical assembly. Adv. Mater. 2008, 20, 3543-3549. [CrossRef]

17. Liu, H.; Xu, J.; Li, Y.; Li, Y. Aggregate Nanostructures of Organic Molecular Materials. Acc. Chem. Res. 2010, 43, 1496-1508. [CrossRef]

18. Shao, S.; Rajendiran, V.; Lovell, J.F. Metalloporphyrin nanoparticles: Coordinating diverse theranostic functions. Coord. Chem. Rev. 2019, 379, 99-120. [CrossRef] [PubMed]

19. Magna, G.; Monti, D.; di Natale, C.; Paolesse, R.; Stefanelli, M. The assembly of porphyrin systems in well-defined nanostructures: An update. Molecules 2019, 24, 4307. [CrossRef] [PubMed]

20. Wang, Z.; Medforth, C.J.; Shelnutt, J.A. Porphyrin Nanotubes by Ionic Self-Assembly. J. Am. Chem. Soc. 2004, 126, 15954-15955. [CrossRef]

21. Lee, S.J.; Hupp, J.T.; Nguyen, S.T. Growth of narrowly dispersed porphyrin nanowires and their hierarchical assembly into macroscopic columns. J. Am. Chem. Soc. 2008, 130, 9632-9633. [CrossRef]

22. Shee, N.K.; Kim, M.K.; Kim, H.-J. Supramolecular Porphyrin Nanostructures Based on Coordination-Driven Self-Assembly and Their Visible Light Catalytic Degradation of Methylene Blue Dye. Nanomaterials 2020, 10, 2314. [CrossRef]

23. Oliveras-González, C.; di Meo, F.; González-Campo, A.; Beljonne, D.; Norman, P.; Simón-Sorbed, M.; Linares, M.; Amabilino, D.B. Bottom-Up Hierarchical Self-Assembly of Chiral Porphyrins through Coordination and Hydrogen Bonds. J. Am. Chem. Soc. 2015, 137, 15795-15808. [CrossRef] [PubMed]

24. Zhang, C.; Chen, P.; Dong, H.; Zhen, Y.; Liu, M.; Hu, W. Porphyrin supramolecular 1D structures via surfactant-assisted self-assembly. Adv. Mater. 2015, 27, 5379-5387. [CrossRef]

25. Yamamoto, K.; Imaoka, T.; Tanabe, M.; Kambe, T. New horizon of nanoparticle and cluster catalysis with dendrimers. Chem. Rev. 2019, 120, 1397-1437. [CrossRef] [PubMed]

26. Drobizhev, M.; Stepanenko, Y.; Rebane, A.; Wilson, C.J.; Screen, T.E.O.; Anderson, H.L. Strong Cooperative Enhancement of Two-Photon Absorption in Double-Strand Conjugated Porphyrin Ladder Arrays. J. Am. Chem. Soc. 2006, 128, 12432-12433. [CrossRef] [PubMed]

27. Smith, A.R.; Ruggles, J.L.; Yu, A.; Gentle, I.R. Multilayer Nanostructured Porphyrin Arrays Constructed by Layer-by-Layer Self-Assembly. Langmuir 2009, 25, 9873-9878. [CrossRef] [PubMed]

28. Abd El-Mageed, A.I.A.; Ogawa, T. Supramolecular structures of terbium(iii) porphyrin double-decker complexes on a singlewalled carbon nanotube surface. RSC Adv. 2019, 9, 28135-28145. [CrossRef]

29. Maeda, C.; Toyama, S.; Okada, N.; Takaishi, K.; Kang, S.; Kim, D.; Ema, T. Tetrameric and Hexameric Porphyrin Nanorings: Template Synthesis and Photophysical Properties. J. Am. Chem. Soc. 2020, 142, 15661-15666. [CrossRef] 
30. Murphy, R.B.; Norman, R.E.; White, J.M.; Perkins, M.V.; Johnston, M.R. Tetra-porphyrin molecular tweezers: Two binding sites linked via a polycyclic scaffold and rotating phenyl diimide core. Org. Biomol. Chem. 2016, 14, 8707-8720. [CrossRef]

31. Slagt, F.V.; van Leeuwen, P.W.N.M.; Reek, J.N.H. Multicomponent Porphyrin Assemblies as Functional Bidentate Phosphite Ligands for Regioselective Rhodium-Catalyzed Hydroformylation. Angew. Chem. Int. Ed. 2003, 42, 5619-5623. [CrossRef]

32. Ballester, P.; Oliva, A.I.; Costa, A.; Deyà, P.M.; Frontera, A.; Gomila, R.M.; Hunter, C.A. DABCO-Induced Self-Assembly of a Trisporphyrin Double-Decker Cage: Thermodynamic Characterization and Guest Recognition. J. Am. Chem. Soc. 2006, 128, 5560-5569. [CrossRef]

33. Huang, C.; Shen, B.; Wang, K.; Lu, J.; Sun, X. Rigid Trisporphyrin with 1,3,5-Triazine Core: Synthesis, Spectroscopy, and DABCO-Induced Self-Assembly Properties. J. Porphyrins Phthalocyanines 2020, 24, 1066-1073. [CrossRef]

34. Seo, J.-W.; Jang, S.Y.; Kim, D.; Kim, H.-J. Octupolar trisporphyrin conjugates exhibiting strong two-photon absorption. Tetrahedron 2008, 64, 2733-2739. [CrossRef]

35. Oliva, A.I.; Ventura, B.; Würthner, F.; Camara-Campos, A.; Hunter, C.A.; Ballester, P.; Flamigni, L. Self-Assembly of Double-Decker Cages Induced by Coordination of Perylene Bisimide with a Trimeric Zn Porphyrin: Study of the Electron Transfer Dynamics Between the Two Photoactive Components. Dalton Trans. 2009, 4023-4037. [CrossRef] [PubMed]

36. Ballester, P.; Costa, A.; Castilla, A.M.; Deyà, P.M.; Frontera, A.; Gomila, R.M.; Hunter, C.A. DABCO-Directed Self-Assembly of Bisporphyrins (DABCO = 1,4-Diazabicyclo[2.2.2] octane). Chem. Eur. J. 2005, 11, 2196-2206. [CrossRef] [PubMed]

37. Ercolani, G. Thermodynamics of Metal-Mediated Assemblies of Porphyrins. In Structure and Bonding; Springer: Berlin/Heidelberg, Germany, 2006; Volume 121, pp. 167-215.

38. Taylor, P.N.; Anderson, H.L. Cooperative Self-Assembly of Double-Strand Conjugated Porphyrin Ladders. J. Am. Chem. Soc. 1999, 121, 11538-11545. [CrossRef]

39. Binstead, R.A.; Zuberbühler, A.D.; Jung, B. SPECFIT/32, V. 3.0.23; Spectrum Software Associates: Marlborough, MA, USA, 2004. 